\title{
PENGARUH KEPEMIMPINAN, BUDAYA ORGANISASI DAN KOMITMEN ORGANISASI TERHADAP KINERJA MANAJEMEN MUTU (Studi pada AKPELNI Semarang)
}

\author{
Retno Indriyati \\ Akademi Pelayaran Niaga Indonesia Semarang \\ Email: retnoindry@yahoo.co.id
}

\begin{abstract}
Abstrak
Tujuan penelitian ini adalah untuk menganalisis pengaruh kepemimpinan, budaya orgnaisasi dan komitmen organisasi terhadap kinerja mutu manajemen. Kinerja manajemen mutu dalam penelitian ini adalah penerapan sistem manajemen mutu berdasarkan ISO 9001: 2008 di AKPELNI Semarang. Populasi penelitian adalah seluruh dosen dan karyawan sejumlah 92 orang. Responden dipilih secara acak dengan menggunakan Rumus Slovin sejumlah 75 orang. Analisis data menggunakan analisis regresi linier berganda dengan alat bantu SPSS v. 16. Hasil penelitian memperlihatkan bahwa kepemimpinan, budaya organisasi dan komitmen organisasi memiliki pengaruh positif dan signifikan terhadap kinerja manajemen mutu.
\end{abstract}

Kata kunci: kepemimpinan, budaya organisasi, komitmen organisasi, kinerja mutu manajemen.

\begin{abstract}
The purpose of this study is to analyze the influence of leadership, cultural organization and organizational commitment toward quality management performance. The quality management performance in this research is the application of quality management system based on ISO 9001:2008 in AKPELNI Semarang. The population is all lecturers and employees of 92 people. Respondents were randomly selected using Slovin formula of 75 people. Data analysis using multiple linear regression analysis with SPSS v. 16. The results show that leadership, organizational culture and organizational comitmen have a positive and significant influence on the performance of quality management.
\end{abstract}

Keywords: leadership, organizational culture, organizational commitment, quality management performance. 


\section{PENDAHULUAN}

Sebagai salah satu PTS Maritim yang diandalkan di Indonesia, AKPELNI berusaha terus mengembangkan mutu pendidikan maupun pelayanannya. Dalam penerapannya, setiap 6 bulan sekali diadakan audit mutu internal dan setiap setahun sekali diadakan audit mutu eksternal guna melihat konsistensi terhadap penerapan sistem manajemen mutu tersebut yang menjadi prinsip dasar dalam melaksanakan sistem manajemen mutu.

Hasil audit eksternal tersebut, menjadi tolok ukur bagi badan sertifikasi ISO untuk memberikan rekomendasi terhadap sertifikasi yang dimiliki AKPELNI. Selain dari ISO, AKPELNI juga diaudit setahun sekali oleh Direktorat Perkapalan dan Kepelautan (Ditkapel) Perhubungan Laut dan Pusat Pengembangan Sumber Daya Manusia (PPSDM) Perhubungan laut. Bahkan pada tahun 2010, dari 6 Lembaga Maritim di Indonesia yang diaudit oleh EMSA, AKPELNI merupakan satu-satunya Lembaga swasta yang mewakili.

Dalam penerapan ISO 9001:2008 tidak terlepas dari seorang pemimpin. Pimpinan mempunyai tugas untuk memadukan unsur-unsur pendidikan demi terciptanya pendidikan yang efektif. Yukl (2007) mendefinisikan kepemimpinan sebagai proses mempengaruhi orang lain untuk memahami dan setuju dengan apa yang harus mereka lakukan dan bagaimana melakukan tugas tersebut secara efektif, serta proses untuk memfasilitasi upaya individu dan kelompok mencapai tujuan bersama (shared goal). Sallis (2006) menyatakan bahwa kepemimpinan adalah unsur penting dalam TQM. Kepemimpinan adalah kemampuan dan ketrampilan yang dimiliki untuk mempengaruhi orang lain, terutama bawahannya untuk berpikir dan bertindak sehingga melalui perilaku yang positif ia memberikan sumbangsih nyata dalam pencapaian organisasi. Menurut Robbins (2001) ada 3 faktor yang menentukan efektifitas kepemimpinan yaitu: leader behaviour, sub ordinate dan situation.

Selain kepemimpinan, budaya organisasi juga merupakan hal yang sangat penting dalam penerapan sistem manajemen mutu. Budaya organisasi merupakan kebiasaan, tradisi dan tata cara umum dalam melakukan sesuatu dan sebagian besar berasal dari pendiri organisasi, yang berpengaruh pada perilaku karyawan yang pada akhirnya juga berpengaruh terhadap organisasi (Falikhatun, 2003). Robbin dan Judge (2007) mendefinisikan budaya organisasi sebagai sebuah sistem makna bersama yang dianut oleh para anggota organisasi yang membedakan organisasi tersebut dengan organisasi lain.

Dalam penerapan sistem manajemen mutu hal yang paling penting adalah komitmen organisasi. Mitchell dalam Rivai (2004) menyatakan bahwa komitmen organisasi merupakan loyalitas dan identifikasi individu terhadap organisasi. Mereka yang mempunyai komitmen tinggi dan rendah absensinya cenderung lebih bertahan daripada mereka yang mempunyai komitmen rendah. Dalam penerapan sistem manajemen mutu, komitmen dari semua elemen sangat diperlukan karena sistem manajemen mutu adalah suatu proses dimana dibutuhkan keterlibatan semua karyawan dari top manajemen sampai karyawan yang paling rendah tingkatannya. Sistem manajemen mutu tidak akan bisa tercapai tanpa komitmen dan keterlibatan semua karyawan.

Berdasarkan hal tersebut maka perumusan masalah dalam penelitian ini adalah bagaimana pengaruh kepemimpinan, budaya organisasi dan komitmen organisasi terhadap kinerja manajemen mutu berdasarkan ISO 9001:2008?

\section{METODE PENELITIAN}

Populasi dalam penelitian ini adalah dosen dan karyawan tetap Akpelni Semarang sebanyak 92 orang. Teknik pengambilan sampel secara acak 
sederhanan dengan menggunakan Rumus Slovin, sehingga responden penelitian sejumlah 75 orang. Analisis data menggunakan analisis regresi linier berganda dengan alat bantu SPSS V.16

\section{HASIL DAN PEMBAHASAN \\ Analisis Deskriptif}

Responden terdiri dari laki-laki sebanyak 57 orang (76 \%) dan perempuan sebanyak 18 orang (24\%), sehingga diketahui jumlah responden laki-laki lebih banyak daripada responden perempuan. Umur responden berusia antara $\leq 25$ tahun, yaitu sebanyak 21 orang (28\%). Banyaknya responden yang berusia 26 35 tahun yaitu sebanyak 12 orang (16\%), responden yang berusia 19 tahun yaitu sebesar 19 orang $(25 \%)$ dan responden yang berusia $>45$ tahun 23 orang $(0,31 \%)$. Hal ini disebabkan untuk mencari dosen profesi yang masih produktif sangat sulit.Sehingga dosen profesi yang ada kebanyakan berusia lanjut. Responden dengan tingkat pendidikan Diploma paling banyak yaitu 27 orang (36\%). Mereka kebanyakan bekerja dibidang ketarunaan yaitu sebagai Pembina Taruna (Bintar) di Asrama AKPELNI. Sedangkan responden yang berijasah SMA sebanyak 13 orang atau $17,3 \%$ dan bekerja sebagai satpam, driver maupun tenaga pendukung lainnya. Sedangkan responden yang berpendidikan S1 sebagian besar adalah tenaga administrasi dan sebagian dosen yang sedang melanjutkan S2. Menunjukkan bahwa responden yang memiliki masa kerja antara 0-5 tahun sebanyak 38 orang atau 50, $6 \%$, responden yang memiliki masa kerja 6-10 tahun sebanyak 5 orang atau $6,7 \%$, responden yang memiliki masa kerja 11-20 tahun sebanyak 26

\section{Uji Reliabilitas}

Uji reliabilitas dilakukan untuk mengetahui seberapa jauh hasil penelitian dikatakan konsisiten. Dengan bantuan program SPSS dapat dilakukan pengukuran reliabilitas dengan uji statistik cronbach alpha minimal 0,6 adalah reliabel. Hasil uji reliabilitas yang secara ringkas disajikan pada Tabel 1, diketahui nilai alpha semuanya di atas 0,6 sehingga disimpulkan data memenuhi uji reliabilitas (Ghozali, 2006).

\section{Uji Normalitas}

Berdasarkan hasil pengujian SPSS, Normal Probability Plot yang terbentuk adalah seperti Gambar 1. Jika dilihat berdasarkan grafik tersebut, maka residual dari regresi berdistribusi normal. Hal ini karena semua data menyebar mengikuti garis Normalitas.

\section{Uji Multikolinieritas}

Multikolinearitas berarti adanya hubungan linear yang "sempurna" atau pasti, diantara beberapa atau semua variabel yang menjelaskan dari model regresi. Istilah multikolinearitas berkenaan dengan terdapatnya lebih dari satu hubungan linear pasti, dan istilah kolinearitas dengan derajatnya satu hubungan linear (Gujarati, 1999;157).

Menurut Ghozali (2001) multikolinearitas dapat juga dilihat dari nilai Tolerance dan lawannya Variance Inflation Factor (VIF). Kedua ukuran ini menunjukkan setiap variabel bebas manakah yang dijelaskan oleh variabel bebas lainnya. Dalam pengertian sederhana setiap variabel bebas menjadi variabel terikat dan diregresi terhadap variabel bebas lainnya. Tolerance mengukur variabilitas variabel bebas yang terpilih yang tidak dapat dijelaskan oleh variabel bebas lainnya. Jadi nilai tolerance rendah sama dengan nilai VIF tinggi (karena VIF $=1 /$ tolerance) dan menunjukkan adanya kolinearitas yang tinggi. Nilai cutoff yang umum dipakai adalah nilai tolerance lebih 0,10 atau sama dengan nilai VIF di kurang 10. Setiap analisa harus menentukan tingkat kolinearitas yang masih dapat ditolerir.

Hasil analisis sebagaimana terlihat pada Tabel 2 untuk ketiga variabel independen, angka VIF kurang dari 10 
$(1,788 ; 2,117$ dan 1,415). Demikian juga dengan nilai Tolerance lebih dari 0,1 yaitu 0,$559 ; 0,472$ dan 0,707 . Dengan demikian dapat disimpulkan model regresi tersebut tidak terdapat problem multikolinieritas. Maka model regresi yang ada layak untuk dipakai.

\section{Uji Heteroskedastisitas}

Ghozali (2001;77) berpendapat bahwa Uji heterokedastisitas bertujuan menguji apakah dalam model regresi terjadi ketidaksamaan variance dari residual satu pengamatan ke pengamatan yang lain. Jika variance dari residual satu pengamatan ke pengamatan lain tetap, maka disebut homoskedastisitas dan jika berbeda disebut heterokedastisitas. Model regresi yang baik adalah yang homokedastisitas atau tidak terjadi heteroskedastisitas.

Deteksi adanya Heterokedastisitas dengan melihat ada tidaknya pola tertentu p pada grafik, di mana sumbu $\mathrm{X}$ adalah $\mathrm{Y}$ yang telah diprediksi, dan sumbu $X$ adalah residual ( $\mathrm{Y}$ prediksi - Y sesungguhnya) yang telah di-studentized. (Santoso, 2000). Adapun grafik hasil pengujian dengan SPSS adalah seperti pada Gambar 2.

Dari grafik di Gambar 2 terlihat titik-titik yang menyebar secara acak, tidak membentuk suatu pola tertentu yang jelas, serta tersebar baik di atas maupun di bawah angka 0 (nol) pada sumbu Y. Hal ini berarti tidak terjadi Heteroskedastisitas pada model regresi, sehingga model regresi layak dipakai untuk keputusan untuk melakukan migrasi.

\section{Uji Model}

Uji F (F-test) dimaksudkan untuk mengetahui pengaruh variabel-variabel independen (kepemimpinan, budaya organisasi dan komitmen organisasi) secara simultan (bersama-sama) terhadap penerapan sistem manajemen mutu. Adapun hasil perhitungan uji $\mathrm{F}$ dapat dilihat pada Tabel 3.

Dari hasil perhitungan didapat nilai $\mathrm{F}$ hitung sebesar 43,361 dengan $\mathrm{P}$ value sebesar 0,000. Apabila dilihat nilai $\mathrm{P}$ value yang kurang dari 0,05 berarti Ho ditolak. Hal ini berarti bahwa model regresi yang digunakan untuk memprediksi penerapan sistem manajemen mutu dapat digunakan untuk memprediksi penerapan sistem manajemen mutu di AKPELNI Semarang.

\section{Koefisien Determinasi}

Hasil perhitungan nilai Koefisien Determinasi $\left(\mathrm{R}^{2}\right)$ dapat dilihat pada Tabel 3. Berdasarkan hasil perhitungan estimasi regresi, diperoleh nilai Koefisien Determinasi yang disesuaikan (adjusted $\mathrm{R}^{2}$ ) adalah 0,647 artinya 64,7 persen variasi dari semua variabel bebas (kepemimpinan, budaya organisasi dan komitmen organisasi) dapat menerangkan variabel tak bebas (penerapan sistem manajemen mutu), sedangkan sisanya sebesar 35,3 persen diterangkan oleh variabel lain yang tidak diajukan dalam penelitian ini.

\section{Pengujian Hipotesis}

Pada pengujian hipotesis dilakukan dengan menggunakan Uji $\mathrm{t}$ (t-test). Uji $\mathrm{t}$ (t-test) ini dimaksudkan untuk mengetahui pengaruh secara parsial (individu) variabel-variabel independen (kepemimpinan, budaya organisasi dan komitmen organisasi) terhadap variabel dependen (penerapan sistem manajemen mutu) atau menguji signifikansi konstanta dan variabel dependen. Adapun hasil perhitungan Uji t (t-test) dapat dilihat pada Tabel 3.

Hasil perhitungan hipotesis pertama, didapat nilai t hitung sebesar 2,807 dengan tingkat signifikansi sebesar 0,006, sehingga disimpulkan bahwa kepemimpinan memiliki pengaruh positif dan signifikan terhadap penerapan kinerja manajemen mutu.

Hasil perhitungan hipotesis kedua, didapat nilai t hitung sebesar 4,176 dengan tingkat signifikansi sebesar 0,000 . sehingga disimpulkan bahwa budaya organisasi memiliki pengaruh positif dan 
signifikan terhadap kinerja manajemen mutu.

Hasil perhitungan hipotesis ketiga, didapat nilai t hitung sebesar 3,104 dengan tingkat signifikansi sebesar 0,003, sehingga disimpulkan bahwa komitmen organisasi memiliki pengaruh positif dan signifikan terhadap kinerja manajemen mutu.

Tabel 1. Hasil Uji Reliabilitas

\begin{tabular}{lcc}
\hline \multicolumn{1}{c}{ Variabel } & Nilai Alpha & Keputusan \\
\hline Kepemimpinan & 0,890 & Reliabel \\
Budaya organisasi & 0,899 & Reliabel \\
Komitmen organisasi & 0,886 & Reliabel \\
Kinerja manajemen mutu & 0,931 & Reliabel \\
\hline
\end{tabular}

Sumber : Data Primer yang diolah, 2013

Tabel 2. Hasil Uji Multikolinieritas

\begin{tabular}{lcc}
\hline \multicolumn{1}{c}{ Variabel } & Tolerance & VIF \\
\hline Kepemimpinan & 0,559 & 1,788 \\
Budaya organisasi & 0,472 & 2,117 \\
Komitmen organisasi & 0,707 & 1,415 \\
\hline
\end{tabular}

Sumber : Data Primer yang diolah, 2013

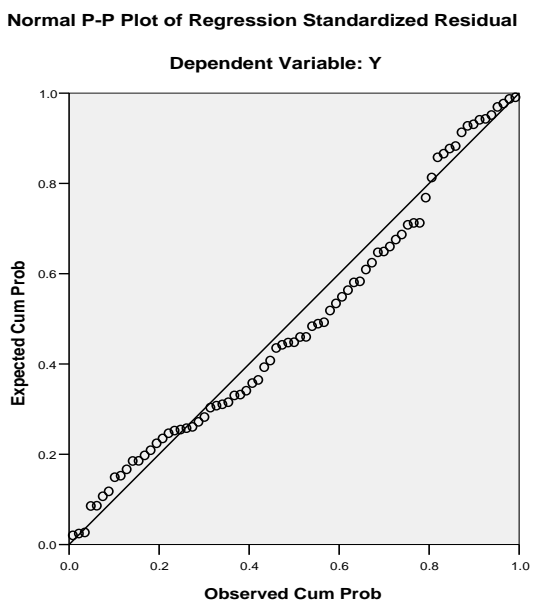

Gambar 1. Grafik Uji Normalitas

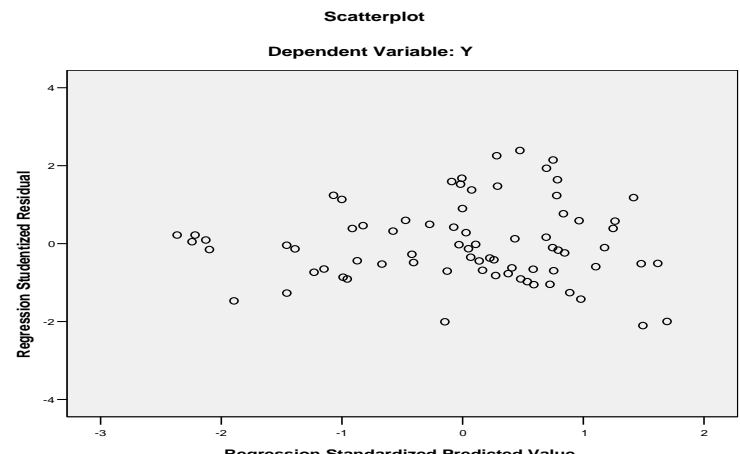

Gambar 2. Uji Heteroskedastisitas 
Tabel 3. Hasil Uji Regresi Linier Berganda

\begin{tabular}{lccccc}
\hline Variabel Independen & $\begin{array}{c}\text { Unstandardized } \\
\text { Coefficients }\end{array}$ & $\begin{array}{c}\text { Standardized } \\
\text { Coefficients }\end{array}$ & $\mathbf{t}$ & Sig & Ket \\
\hline (Constant) & 8,892 & & 1,655 & 0,102 & \\
Kepemimpinan & 0,333 & 0,265 & 2,807 & 0,000 & Signifikan \\
Budaya organisasi & 0,487 & 0,428 & 4,176 & 0,000 & Signifikan \\
Komitmen organisasi & 0,380 & 0,260 & 3,104 & 0,003 & Signifikan \\
\hline
\end{tabular}

Variabel Dependen : Kinerja manajemen mutu

$\mathrm{R}=0,804, R$ Square $=0,647$, Adjusted $R$ Square $=0,632$

F Hitung $=43,361$, Sig.F $=0,000$

Sumber : Data Primer yang diolah, 2013

\section{Pembahasan}

Berdasarkan hasil analisis maka dapat disimpulkan bahwa variabel kepemimpinan, budaya organisasi dan komitmen organisasi berpengaruh positif terhadap penerapan sistem manajemen mutu di AKPELNI Semarang. Hal ini mengandung arti semakin baik kepemimpinan, budaya organisasi dan komitmen organisasi pada karyawan AKPELNI Semarang berakibat pada meningkatnya penerapan sistem manajemen mutu di AKPELNI Semarang.

Pengaruh terbesar pada penerapan sistem manajemen mutu di AKPELNI adalah budaya organisasi. Adanya pengaruh budaya organisasi terhadap penerapan sistem manajemen mutu menandakan bahwa sistem makna bersama yang dianut oleh para karyawan di AKPELNI Semarang yang membedakan organisasi tersebut dengan organisasi yang lain dapat menentukan keberhasilan penerapan sistem manajemen mutu pada organisasi tersebut. Budaya organisasi pada AKPELNI Semarang yang efektif akan membantu organisasi mengantisipasi dan beradaptasi dengan perubahan lingkungan terutama dalam penerapan sistem manajemen mutu. Keharmonisan tujuan semacam ini akan membangun kekompakan, loyalitas dan komitmen organisasional yang pada gilirannya akan mengurangi kecenderungan karyawan untuk meninggalkan organisasi sehingga dapat menentukan keberhasilan penerapan sistem manajemen mutu di AKPELNI Semarang. Hal ini sesuai dengan pendapat
Robbins dan Judge (2007) bahwa budaya organisasi bisa dalam kondisi kuat maupun lemah tergantung pada berbagai faktor yang mempengaruhi seperti kepaduan, konsesus, nilai dan komitmen individu terhadap tujuan bersama.

Komitmen organisasi sebagai suatu keadaan sejauh mana seorang karyawan memihak pada suatu organisasi tertentu dan tujuannya, dan berniat memelihara keanggotaan dalam organisasi tersebut untuk menjaga kelangsungan organisasi tersebut. Adanya komitmen organisasi yang kuat pada karyawan AKPELNI Semarang menandakan adanya loyalitas karyawan terhadap kelangsungan organisasi AKPELNI Semarang. Komitmen organisasi terhadap sistem manajemen mutu ISO harus dapat dicerminkan oleh komitmen karyawan dari manajemen puncak, manajemen level menengah sampai kepada karyawan paling rendah dalam menerapkan klausul-klausul ISO yang sudah ditetapkan. Hal tersebut sesuai dengan teori yang dikemukakan oleh Newstrom and Davis (2002), bahwa komitmen organisasional merupakan tingkat dimana individu memihak dan ingin secara kontinyu berpartisipasi aktif dalam organisasi, yang tercermin melalui karakteristik-karakteristi sebagai berikut: (1) adanya keyakinan yang kuat dan penerimaan atas nilai dan tujuan organisasi, (2) kesediaan untuk mengusahakan yang terbaik bagi organisasi, (3) adanya keinginan yang pasti untuk bertahan dalam organisasi. Demikian juga dengan teori yang dikemukakan oleh Allen \& Meyer (1993), yang menge- 
mukakan bahwa komitmen organisasional sebagai sebuah keadaan psikologi yang mengkarakteristikkan hubungan karyawan dengan organisasi atau implikasinya yang mempengaruhi apakah karyawan akan tetap bertahan dalam organisasi atau tidak.

Kepemimpinan berpengaruh positif terhadap penerapan Sistem Manajemen Mutu di AKPELNI Semarang. Penerapan Sistem Manajemen Mutu di AKPELNI Semarang dimulai dari pimpinan, sehingga seorang pemimpin harus dapat menciptakan dan mengimplementasikan visi dan strategi yang sesuai dengan konteks organisasi dalam menerapkan sistem manajemen mutu. Kemampuan adaptasi harus ditingkatkan dari waktu ke waktu dengan mengkombinasikan antara sukses organisasi dan fokus kepemimpinan yang spesifik. Para pemimpin harus dapat memastikan bahwa karyawan menerima filosofi organisasi atau seperangkat nilai yang menekankan pelayanan pada unsur pokok organisasi, konsumen, pemegang saham, karyawan, dan peningkatan kepemimpinan. Sementara itu infrastruktur harus dapat mendorong secara konsisten dan mendukung filosofi atau nilai dasar organisasi dalam memuaskan kebutuhan unsur pokok organisasi dan peningkatan kepemimpinan. Fungsi pemimpin di AKPELNI Semarang adalah memandu, menuntun, membimbing, memotivasi, menjalin komunikasi yang baik, mengorganisasi, mengawasi dan membawa kelompoknya pada tujuan organisasi AKPELNI yang telah ditetapkan.

\section{PENUTUP}

\section{Kesimpulan}

Upaya AKPELNI Semarang untuk mendapatkan peningkatan kualitas manajemen mutu dapat dilakukan dengan meningkatkan aspek kepemimpinan, budaya organisasi dan komitmen organisasi.

\section{Saran}

Upaya peningkatan kualitas manajemen mutu dapat dilakukan melalui beberapa cara, yaitu: meningkatkan kekompakan, semangat kebersamaan dan kekeluargaan di lingkungan AKPELNI Semarang, meningkatkan sarana dan prasarana untuk mendukung pekerjaan di setiap bagian termasuk didalamnya menciptakan suasana dan tata ruang yang nyaman dan menyenangkan serta pemberian reward punishment kepada karyawan tanpa pandang bulu, pengembangan karyawan melalui pelatihan / kursus, melibatkan karyawan pada rapat ataupun kegiatan lembaga yang berkaitan dengan pengambilan keputusan dan kebijakan lembaga misalnya penyusunan Rencana Anggaran Pendapatan dan Belanja serta mengikutsertakan karyawan pada berbagai acara yang diselenggarakan oleh lembaga misalnya acara Dies Natalis, perlombaan olahraga dan sebagainya.

\section{DAFTAR PUSTAKA}

Allen, N. J., \& Meyer, J. P. (1993). Organizational commitment: Evidence of career stage effects? Journal of Business Research, 26, 49-61.

Arikunto, S. (2009). Manajemen Penelitian, Jakarta: Rineka Cipta.

Danang, S. \& Burhanudin. (2011). Perilaku Organisasional Yogyakarta: Penerbit CAPS.

Deming, W.E. (1986). Out of the crisis. Cambridge, MA, Massachusetts Institute of Technology, Center forAdvanced Engineering Study

Desler, G. (2004). Manajemem Sumber Daya Manusia, terjemahan Eli Tanya, Jakarta: PT. Indeks.

Dongoran, J. (2004). Siklus Hidup Organisasi dan Gaya Kepemimpinan, Jurnal Ekonomi Bisnis dan Ekonomi. $\mathrm{X}(1), 129-157$. 
Falikhatun. (2003). Pengaruh Budaya Organisasi, Locus of Control, dan Penerapan Sistem Informasi terhadap Kinerja Aparat Unit-Unit Publik. Empirika. 16(2), 263-281.

Gaspersz, V. (2005). Total Quality Management. Jakarta: Gramedia.

Ghozali, I. (2006). Aplikasi Analisis Multivariate dengan Program SPSS, Semarang: Penerbit Universitas Diponegoro.

Gujarati, D. (2005). Ekonometrika Dasar, Edisi Ketujuh. Jakarta: Erlangga.

Hees, P. \& Siciliano, J. (1996). Management Responsibility for Performance. United States : McGraw Hill, Inc.

Konsultan ISO, 2 Desember 2011 03:12 AM | ISO 9001:2008. Melalui www.google.com.

Kreitner, R., \& Angelo, K. (2005). Perilaku Organisasi. buku 2 (terjemahan). Jakarta: Salemba Empat.

Newstorm \& Davis. (2002). Organisational Behavior. United States: The McGraw-Hill Companies, Inc.

Rivai, F. (2004). Kiat Memimpin Dalam Abad 21. Jakarta: PT. Raja Grafindo Persada.

Robbin, S.P. \& Judge, T.A. (2007). Perilaku Organisasi, buku 1 (terjemahan). Jakarta: Salemba Empat.

Robbins, S.P. (2002). Perilaku Organisasi. Jakarta, Erlangga

Safaria, T. (2004). Kepemimpinan. Yogyakarta: Graha Ilmu.
SAI Global (2008). Standard Persyaratan ISO 9001:2008.

Sallis, E. (2006) Total Quality Management In Education, Terjemahan Ahmad Ali Riyadi, Yogyakarta : IRCISoD.

Susilo, W. (2003). Audit Mutu Internal : Panduan Praktis Para Praktisi Manajemen Mutu dan Auditor Mutu Internal, Jakarta: Vorqistatama Binamega.

Syafarudin. (2003). Manajemen Mutu Terpadu dalam Pendidikan, Jakarta: PT. Gramedia Widiasarana Indonesia.

Tjiptono, F. (2004). Total Quality Service. Yogyakarta: Andi Offset.

Yukl, G. (2007). Kepemimpinan Dalam Organisasi. Edisi Kelima (Terjemahan). Jakarta: PT. Indeks. 